\title{
Formation and characterization of $\mathrm{Rh}$-Mo bimetallic layers on the $\mathrm{TiO}_{2}\left(\begin{array}{lll}1 & 1 & 0\end{array}\right)$ surface
}

\author{
László Bugyi, László Óvári, János Kiss* \\ Reaction Kinetics Research Laboratory, Institute of Nanochemistry and Catalysis, Chemical Research Center of the Hungarian Academy of Sciences, P.O. Box 168, \\ H-6701 Szeged, Hungary \\ Department of Physical Chemistry and Material Science, University of Szeged, H-6720 Szeged, Dóm sqr. 7, Hungary
}

\section{A R T I C L E I N F O}

\section{Article history:}

Received 10 June 2009

Accepted for publication 30 July 2009

Available online 8 August 2009

\section{Keywords:}

$\mathrm{TiO}_{2}\left(\begin{array}{lll}1 & 1 & 0\end{array}\right)$

Mo

$\mathrm{Rh}$

Bimetallic

Alloying

Encapsulation

Thermal activation

Interfacial reaction

\begin{abstract}
A B S T R A C T
The investigation of $\mathrm{Rh}$, Mo and Rh-Mo nanosized clusters formed by physical vapor deposition on $\mathrm{TiO}_{2}\left(\begin{array}{lll}1 & 1 & 0\end{array}\right)$ single crystal was performed by X-ray Photoelectron Spectroscopy (XPS), Low Energy Ion Scattering (LEIS) and Auger Electron Spectroscopy (AES). There was no sign for site-exchange between Mo and $\mathrm{Rh}$ atoms during deposition of Mo onto Rh particles at $330 \mathrm{~K}$. Mixing between Ti and Mo ions was facilitated at the Mo particle-titania interface due to reaction at 550-700 $\mathrm{K}$. The redox process between titania and Mo deposit was hindered at $330 \mathrm{~K}$ by forming predeposited rhodium layer $\left(\Theta_{\mathrm{Rh}}=2.0 \mathrm{ML}\right)$, but reached nearly the same extent as without Rh after moderate heating to $600 \mathrm{~K}$. The encapsulation of Rh by titania was complete by about $700 \mathrm{~K}$ in the presence of $1.2 \mathrm{ML}$ Mo, in case of Mo-predeposition and Mo-postdeposition as well. Elevating the temperature of $\mathrm{TiO}_{2} / \mathrm{Rh}$-Mo layers above $700 \mathrm{~K}$, these metals form alloy at the Mo-Rh interface irrespective of deposition sequences.
\end{abstract}

(c) 2009 Elsevier B.V. All rights reserved.

\section{Introduction}

The investigation of bimetallic systems is of interest because of their advantageous, new physical and chemical properties as compared with monometallic layers. Several single crystal studies were performed to study the dissolution of metallic adlayers in another supporting metal under well-defined conditions [1]. However, the investigation of bimetallic nanoparticles in model systems in the author's knowledge is relatively rare. Examples are Pt-Rh [2] and Co-Pd bimetallic systems studied under ultrahigh vacuum conditions $[3,4]$. Recently, it was reported that in the presence of Mo, the dispersion of titania-supported gold particles increased through disruption and their thermal stability was greatly enhanced as a result of Mo-titania interfacial reaction and the lower surface free energy of gold compared to that of molybdenum [5]. The number of gold atoms located on the topmost layer of metal clusters increased also due to $\mathrm{Rh}$ deposition on a gold covered titania surface, although with a different mechanism [6]. On the base of these findings, it seems to be important to study the effect

\footnotetext{
* Corresponding author. Address: Reaction Kinetics Research Laboratory, Institute of Nanochemistry and Catalysis, Chemical Research Center of the Hungarian Academy of Sciences, P.O. Box 168, H-6701 Szeged, Hungary. Tel.: +36 62544 803; fax: +36 62420678 .

E-mail address: jkiss@chem.u-szeged.hu (J. Kiss).
}

of Mo on the structure, stability and catalytic activity of Rh particles supported on single crystalline titania. On the other hand, it is known that the relatively low surface area as well as poor stability of titania structure at high temperature is the main disadvantage of titania while using as a catalyst or a catalyst support. Modification with Mo may overcome these limitations. Moreover, the presence of Mo was found to increase the number and strength of acidic sites on $\mathrm{TiO}_{2}$ leading to enhanced catalytic efficiency in several cases [7].

The Mo-Rh combination was proved to possess outstanding catalytic activity in hydrogenation and hydroformylation reactions [8-11]. There are several explanations concerning the promotion effect of molybdenum, among them is the promotional influence of molybdenum oxides [9] and the alloying between $\mathrm{Rh}$ and Mo [12]. The Mo-Rh system is characterized by a limited solubility of $\mathrm{Rh}$ in Mo ( $0.65 \mathrm{at} \%)$ and a more considerable one of Mo in Rh (at least 10 at\%) [13]. Ab initio calculations confirmed the stability of MoRh, MoRh3 and MoRh 2 compounds [14]. Calculated segregation energy values for Mo atoms from $\mathrm{Rh}$ are positive [15], indicating that $\mathrm{Rh}$ atoms are preferably outside. Note that these statements are related to bulk materials, but for nanosized particles the driving force for atomic location may be different due to the large surface energy of nanoparticles and as a result of gas adsorption under catalytic circumstances [16]. 
In a recent work, the diffusion of Mo atoms was experienced into Pt(1 11 1) crystal at and above $1070 \mathrm{~K}$ [17]. An important observation is that the combination of Mo with platinum gives exceptionally active electrode material for methanol oxidation in aqueous acidic electrolytes [18]. However, it is reasonable to suppose that the promotion of surface reactions by Mo under electrochemical conditions follows different mechanism than under gas atmosphere.

In the present work we focus on the topic of spatial distribution of $\mathrm{Rh}$ atoms being in different amounts on Mo-covered surfaces. Because of the complexity of the system, monometallic layers have to be also characterized. The adsorption behaviour of the bimetallic Rh-Mo particles will be addressed in a separate article.

\section{Experimental}

The experiments were performed in two different ultrahigh vacuum (UHV) chamber (base pressure $<5 \times 10^{-8} \mathrm{~Pa}$ ). The first one was equipped with facilities for AES, TPD and RAIRS measurements, previously described in [19]. AES measurements were performed with a Physical Electronics coaxial-gun single pass CMA, while mass spectrometric and TPD data were collected by a QMS 200 (Balzers) quadrupole mass spectrometer. In the second chamber AES, LEIS and XPS techniques were used (see details in [5]). AES was performed with $2.5 \mathrm{keV}$ primary electron energy, $3 \mathrm{~V}$ modulation and 1-2 $\mu \mathrm{A}$ beam current. AES data were evaluated either plotting the absolute peak-to-peak heights of main peaks (Mo: $186 \mathrm{eV}, \mathrm{C}: 272 \mathrm{eV}, \mathrm{Rh}: 302 \mathrm{eV}, \mathrm{Ti}: 387 \mathrm{eV}, 0: 503 \mathrm{eV}$ ) or Auger ratios calculated with the Ti(387 eV) peak. XPS measurements were carried out by Leybold hemispherical energy analyzer with a constant $100 \mathrm{eV}$ pass energy using factory settings, at a take-off angle of $17^{\circ}$ (with respect to surface normal) using an $\mathrm{Al} \mathrm{K} \alpha \mathrm{X}$-ray anode, which was an ATOMKI product [20]. A SPECS IQE 12/38 ion source was used for LEIS. $\mathrm{He}^{+}$ions of $800 \mathrm{eV}$ kinetic energy were applied at low ion flux equal to $0.03 \mu \mathrm{A} / \mathrm{cm}^{2}$. The incident and detection angles were $50^{\circ}$ (with respect to the surface normal), while the scattering angle was $95^{\circ}$. LEIS spectra were obtained using the same Leybold EA10/100 hemispherical analyzer as for XPS and AES but with the polarity of the voltage biases inverted to detect $\mathrm{He}^{+}$ions. Note that the information depth of LEIS is predominantly restricted to the outermost atomic layer, when performed with noble gases, due to the high tendency of neutralization of noble gas ions in solid materials.

The $\mathrm{TiO}_{2}\left(\begin{array}{lll}1 & 1 & 0\end{array}\right)$ single-crystals were products of PI-KEM. The samples were attached to a Ta plate with an oxide glue (AREMCO, ceramobond 571), and could be heated with a W filament placed behind the Ta plate. The sample temperature was measured by a chromel-alumel thermocouple, attached to the side of the sample with the same adhesive material. The heating and cooling rates during cleaning and all measurements presented here were always less than $2 \mathrm{~K} / \mathrm{s}$, regulated by a computer-controlled circuit. The duration of annealing in stepwise heating experiments was equal to or less than 2 min.

The typical cleaning procedure of titania consisted of $\mathrm{Ar}^{+}$ion bombardment $\left(1.5 \mathrm{keV}, 3 \times 10^{-6} \mathrm{~A} \mathrm{~cm}^{-2}, 300 \mathrm{~K}, 30 \mathrm{~min}\right)$ and annealing at $900 \mathrm{~K}$ for $30 \mathrm{~min}$. The absence of oxygen-treatments resulted in blue-coloured, slightly defective crystal. Note, that after this procedure the contribution of $\mathrm{Ti}^{3+}$ and $\mathrm{Ti}^{2+}$ signals to the $\mathrm{Ti} 2 \mathrm{p}$ photoemission feature was found to be below $3 \%$. The above treatment ensured the appropriate electrical conductivity for electron spectroscopy and high enough defect-density to observe 2D-like growth of Rh-particles in extended coverage range. It is known from previous STM investigations that similar treatments result basically in $(1 \times 1)$ bulk terminated registry, although the presence of $1-2 \%$ of defect sites (OD dots and $1 \mathrm{D}$ strings of $\mathrm{Ti}_{2} \mathrm{O}_{3}$ stoichiometry) can not be excluded [21].
An EGN4 e-beam evaporator of Oxford Applied Research was used for the deposition of Mo and Rh at sample temperature of 200 and $330 \mathrm{~K}$. The ion-current measured at the exit of the evaporator head was 5-15 nA at electron-bombardment potential of $2 \mathrm{kV}$. The two similar $\mathrm{TiO}_{2}\left(\begin{array}{lll}1 & 1 & 0\end{array}\right)$ samples were cleaned and exposed to Rh and Mo vapour in the same way in the two UHV chambers. Special attention was paid to the thorough calibration of the $\mathrm{Rh}$ and Mo coverages in the two chambers by means of uptakecurves taken with AES. In the XPS-LEIS chamber the coverage was also checked by XPS and LEIS [6,22].

\section{Results and discussion}

The interaction between $\mathrm{TiO}_{2}$ surfaces and $\mathrm{Rh}$ is well-documented [23]. The growth of Rh-particles on titania surfaces was addressed by different experimental techniques, like STM, AES $[24,25]$, XPS and LEIS [6,22]. The growth of Rh nanoparticles was found to follow Volmer-Weber mechanism on stoichiometric samples, but the formation of flat particles was observed on reduced, defective surfaces [24,25], termed 2D-like growth [6]. The present work is the continuation of our former studies on the build-up of Rh clusters on titania surfaces [6,22], based on STM, LEIS, AES and XPS data. To estimate the Rh surface coverage we followed the Rh-uptake by AES (not shown). The Rh AES signal as a function of deposition time showed a definite break-point at the end of an initial linear region, indicating the termination of 2D-like particle growth at $0.35 \mathrm{ML}$ Rh coverage, as it was formerly established for a similarly pretreated sample [6].

In Fig. 1 we present XPS and AES data to characterize the progress of interfacial reaction on Mo-covered $\mathrm{TiO}_{2}$ surfaces as a function of temperature. Although the deposition and reaction of Mo with titania at $300 \mathrm{~K}$ and higher temperatures is already documented [26], being influenced by several factors, like the oxidation state of titanium ions and even the evaporation rate of Mo, these complex processes deserve attention under our experimental conditions as well. Since there is scarce information about the uptake of Mo at cryogenic temperatures, we performed deposition on sample held at $200 \mathrm{~K}$. The formation of Mo layers with CVD of $\mathrm{Mo}(\mathrm{CO})_{6}$ was reported [27] and it was established that metallic overlayers could be prepared at lower temperatures as compared to oxidized layers formed by CVD at $300 \mathrm{~K}$ and above. Our XPS measurement reveals (Fig. $1 \mathrm{~A}$ ) that the Ti 2 p peak shapes are similar irrespective of the deposition temperatures of $200 \mathrm{~K}$ or $330 \mathrm{~K}$, suggesting that the interfacial reaction between Mo and titania results in practically the same extent of reduction of $\mathrm{Ti}^{4+}$ ions. This supports that the activation energy for oxidation reaction of Mo in this temperature-range is ensured. The low or zero activation energy corresponding to the low temperatures implies that the reduction of titanium ions and oxidation of Mo atoms located at the interface includes essentially only electron exchange without significant thermally activated movement of $\mathrm{Ti}, \mathrm{O}$ or Mo atoms. The analysis of Mo 3d XPS features (not shown) indicates that the dominant oxidation states for Mo at the relatively large Mo coverages used in the present work are $2+$ and 0 at $330 \mathrm{~K}$, similar to former observations $[28,29]$. On elevating the temperature to $550 \mathrm{~K}$, the extent of reduction of titania increases as shown by the shoulders at the binding energies characteristic of $\mathrm{Ti}^{3+}$ and $\mathrm{Ti}^{2+}$ ions (Fig. 1A). These changes in the XPS spectra reflect that the redox reaction between titania and Mo deposit is more pronounced at higher temperatures, and needs activation energy probably due to a structural rearrangement of the reactants at the interface. Annealing at $900 \mathrm{~K}$ for $2 \mathrm{~min}$ (not shown) restores the Ti 2 p spectrum obtained at $330 \mathrm{~K}$, what is the consequence of reoxidation of reduced titania surface. This is in harmony with the observation that the $\mathrm{O}$-content of a reduced $\left(\mathrm{Ar}^{+}\right.$ion sputtered) 

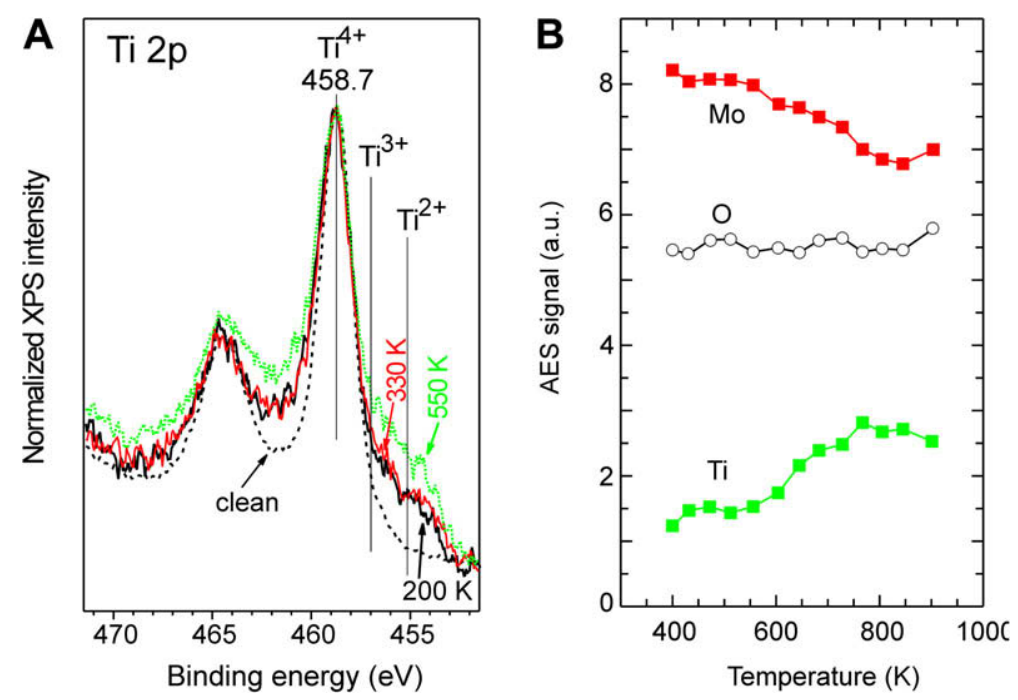

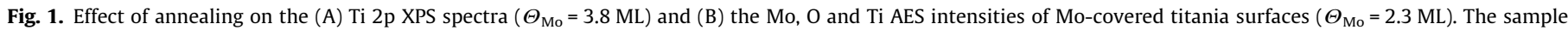
temperatures during Mo deposition were $200 \mathrm{~K}$ and $330 \mathrm{~K}$ (XPS) and $330 \mathrm{~K}$ (AES).

titania surface can be enhanced by annealing above $650 \mathrm{~K}$ (see $\mathrm{O} / \mathrm{Ti}$ AES ratios in Fig. 2B inset).

On annealing a Mo-covered $\left(\Theta_{\mathrm{Mo}}=2.3 \mathrm{ML}\right)$ titania (Fig. 1B) it can be seen that the AES O-signal is stable up to $\sim 850 \mathrm{~K}$, which seems to reflect a constant $\mathrm{O}$-concentration in the near-surface region, while that of Mo and Ti vary at 550-700 K. To interpret these observations we cite some former relevant findings and statements. It was established that the sintering of Mo particles at higher coverages (3.6 ML) begins around above $700 \mathrm{~K}$ [21] and molybdenum nanoparticles (1.2 ML) showed remarkable resistance to sintering during short durations of annealing at $700 \mathrm{~K}$ [30]. Note that the interfacial reaction is explained in the term of oxygen diffusion into Mo particles, but the diffusion of Mo-atoms into the titania lattice, especially at higher temperatures, forming an amorphous interface can not be excluded. It was concluded in a simulation study that Mo atoms are incorporated into the first layer of titania to find energetically most stable position [31]. On the other hand, it was claimed that an annealing procedure pro- motes the diffusion of both constituents of titania lattice between 400 and $700 \mathrm{~K}$, but above $700 \mathrm{~K}$ the titanium ion diffusion from the surface to the bulk was dominant [32]. Cross-checking our XPS and AES results and the findings reported in the literature we conclude that (i) the increase in Ti AES signal at $550-700 \mathrm{~K}$ (Fig. 1B) is not due to sintering, which was formerly observed only above $700 \mathrm{~K}$, but is an indication of the proceeding of oxidation process on elevating the temperature. This redox reaction expectably occurs dominantly at the Mo-titania interface, hence the concomitant decrease in Mo AES signal and increase of Ti-peak may be an indication of site-exchange between Mo and Ti-ions, that is the interfacial formation of a mixed molybdenum-titanium oxide. It is in harmony with a former statement that chemical interactions at metal/oxide interfaces may force metals to diffuse into their oxide supports and/or substrate atoms to the metal surface [33], leading to the formation of interdiffusion zones or mixed oxides. It was established that annealing of a Mo-covered titania surface at $673 \mathrm{~K}$ led to the formation of substitutional molybdenum ions
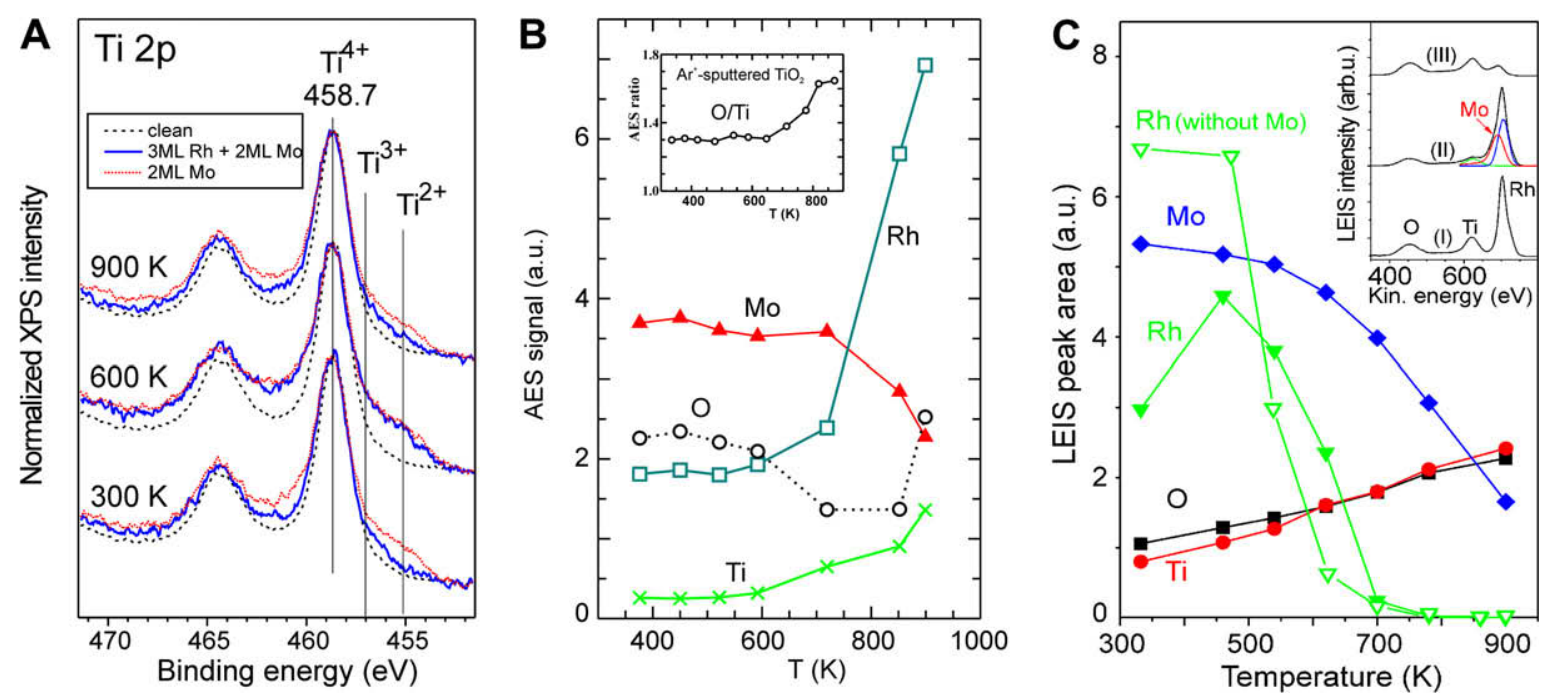

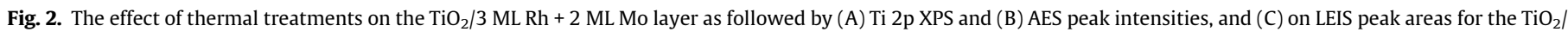

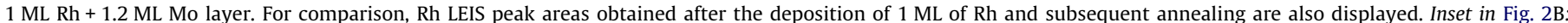

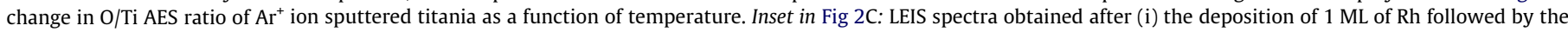
deposition of $1.2 \mathrm{ML}$ of Mo, both at $330 \mathrm{~K}$ and annealing at (ii) $460 \mathrm{~K}$ and (iii) $900 \mathrm{~K}$. 
in titanium sites of the $\mathrm{TiO}_{2}\left(\begin{array}{lll}1 & 1 & 0\end{array}\right)$ substrate [29], while annealing at $853 \mathrm{~K}$ caused the appearance of a substitutional near-surface alloy [34]. (ii) There may be another contribution to the intensity changes shown in Fig. 1B between 550 and $700 \mathrm{~K}$. The surface diffusion of $\mathrm{O}$ atoms from titania to molybdenum surface expectably increases the Ti AES signal of the O-depleted regions, decreases the Mo peak and leads to approximately unchanged $O$ signal. There is some indication for this process by LEIS data (not shown), which reflect constant surface O-coverage in this temperature range accompanied by an increase in Ti-signal and decrease in Mo-peak. It is reasonable to suppose that a redox reaction can proceed at least to some extent at the perimeter of Mo-particles controlled by surface diffusion of O-atoms from the support.

Turning to the Rh-Mo bimetallic system, we first followed by AES the uptake of Rh on a Mo-covered titania surface at $330 \mathrm{~K}$ (not shown). Although a well-defined break-point could not be distinguished on this curve, there is an indication based on the linear change in Rh AES signal that Rh nanoparticles showed a 2D-like growth at $330 \mathrm{~K}$ in an extended coverage range up to about $0.45 \mathrm{ML}$, as related to the Mo-free surface, 0.35 ML. This can be explained partly by the reduction of titania surface by the Mo deposit, since reduced centers represent defects sites, hindering the surface diffusion of Rh atoms to form clusters. On the other hand, the wetting of Mo particles seems to be also preferred because of the lower surface free energy of Rh related to that of Mo, but this probably is not complete due to the formation of $\mathrm{MoO}_{x}$ formed on the Mo particles.

In Fig. $2 \mathrm{~A}$ we compare the change in the peak shapes of Ti $2 \mathrm{p}$ doublets as a result of annealing the metal-free (dashed line), Mo-deposited (2 ML Mo, dotted line) and bimetallic (3 ML Rh + 2 ML Mo, solid line) samples. According to the expectation, predeposited $\mathrm{Rh}$ particles hindered the interfacial reaction of postdeposited Mo-atoms with the surface at the deposition temperature, $300 \mathrm{~K}$, as shown by the lower concentration of $\mathrm{Ti}^{2+}$ and $\mathrm{Ti}^{3+}$ states compared to the Rh-free case. However, it can be seen that after heating to $600 \mathrm{~K}$, the contribution of $\mathrm{Ti}^{2+}$ and $\mathrm{Ti}^{3+}$ states to the Ti 2 p signal is only slightly reduced on the Rh-covered surface, suggesting that the Rh interlayer exerted a limited hindrance for the redox reaction between Mo and titania. Interestingly, the intensity of Rh 3d XPS feature enhanced by about 15\% between 600 and $900 \mathrm{~K}$ (not shown).

The effect of thermal treatment on Rh-covered and Mo-postdeposited surface ( $3 \mathrm{ML} \mathrm{Rh}+2 \mathrm{ML} \mathrm{Mo}$ ) is presented in Fig. 2B. Up to $\sim 600 \mathrm{~K}$, only slight changes can be observed in AES intensities, while above this temperature the $\mathrm{Rh}$ and $\mathrm{Ti}$ signals are intensified, by factors of 3.82 and 5.23 , respectively. The substantial enhancement of Rh AES peak above $700 \mathrm{~K}$ is in sharp contrast to the decrease observed in the absence of molybdenum (see Fig. 3A, full squares). The increase in Rh AES peak in Fig 2B can be explained by spreading of Rh over molybdenum, which would be in harmony with the segregation energies calculated for the Mo-Rh system [15]. The decrease in Mo above $700 \mathrm{~K}$ can be rationalized by sintering and oxidation. The concomitant increase of $\mathrm{Rh}$ - and decay of Mo-signal can also be related to the alloying of Mo with Rh, what can be suggested on the base of known solubility data of Mo in Rh (at $873 \mathrm{~K}$ it is approximately $\sim 10$ at\%) and limited solubility of Rh in Mo ( $\sim 0.65$ at\%) [13]. Here we refer to the well-known fact that alloying between nanoparticles can be facilitated due to their large surface energies or differences in their electronic structure. The steep decrease of $\mathrm{O}$-signal above $\sim 600 \mathrm{~K}$ indicates the removal of $\mathrm{O}$ atoms from titania into dissolved states in Mo nanoparticles, that is the propagation of reaction between titania and Mo particles. To establish the actual temperature range of the thermally activated migration of constituent ions in the near-surface region of our titania sample, we present in the inset of Fig. $2 \mathrm{~B}$ the $\mathrm{O} /$
Ti AES ratio as a function of annealing temperature for an $\mathrm{Ar}^{+}$ ion sputtered surface. There is an indication for enhanced ion mobility above $650 \mathrm{~K}$, which results in the increase of relative O-signal. This is in accordance with former observations [5,32] and shows in harmony with Fig. $2 \mathrm{~A}, 900 \mathrm{~K}$ curve that above $\sim 650 \mathrm{~K}$ the surface stoichiometry of a reduced titania surface begins to restore. On the base of this fact it seems probable that the increase in Rh AES signal is not due to the spreading and stabilization of $\mathrm{Rh}$ on the reduced titania surface, in contrast to what was observed for the Au particles in the presence of Mo on an initially reduced titania sample [5]. The intensity enhancement in $\mathrm{O}$ - and Ti-signals above $850 \mathrm{~K}$ indicates the sintering of Moand Rh-particles.

LEIS data for annealing the $\mathrm{TiO}_{2} / 1 \mathrm{ML} \mathrm{Rh}+1.2 \mathrm{ML}$ Mo layer are presented in Fig. 2C. Note that at $330 \mathrm{~K}$ the Mo-peak was only slightly smaller than for the Rh-free surface after the same amount of Mo-deposition, what indicates that the Rh-concentration on the surface of Mo particles might be very limited or zero, that is a siteexchange between Mo and Rh at this temperature is negligible. The intensity increase of Rh LEIS peak area up to $460 \mathrm{~K}$ can be attributed to desorption of $\mathrm{CO}$ adsorbed during evaporation of Mo. A comparison of Rh-signals between the Mo-free (open triangles) and Mo-covered (full triangles) surfaces shows that the encapsulation process of Rh is suppressed to some extent by Mo-postdeposition, but it is essentially completed in both cases at around $700 \mathrm{~K}$.

It is indicated in Fig. 2A. that the high affinity of Mo towards the $\mathrm{O}$-content of titania is manifested in practically the same extent of reduction of titania at the same low temperature, $600 \mathrm{~K}$ for the Rhpredosed and only Mo-exposed surfaces. On the other hand, LEIS data in Fig. $2 \mathrm{C}$ prove that Rh surface sites uncovered with Mo atoms are nearly completely encapsulated by titania at $\sim 700 \mathrm{~K}$. These observations reflect that the Rh interlayer and Mo overlayers play a minor role in the diffusion processes of oxygen and titanium ions at higher temperatures, $600-800 \mathrm{~K}$.

To understand the complex behaviour of the $\mathrm{TiO}_{2} / \mathrm{Rh}$-Mo bimetallic system on the titania surface, experiments with reverse deposition sequence were also performed. As it is presented in Fig. $3 \mathrm{~A}$, the annealing of mixed adlayer $\left(\mathrm{TiO}_{2} / 2 \mathrm{ML} \mathrm{Mo}+3 \mathrm{ML} \mathrm{Rh}\right)$ resulted in a slight increase in the Rh AES signal up to $\sim 600 \mathrm{~K}$. A comparison with the Rh AES peak intensity change obtained for Mo-free surface (shown also in Fig. 3A, full squares) reveals that the Rh nanoparticles are stabilized in the presence of Mo. This can be explained with the following phenomena: (i) a part of Rh is sticked to the top of Mo nanoparticles, and having a tendency to cover molybdenum in their bimetallic system [15], remains located or even spreads to some extent over the Mo surface, (ii) as a result of heating, the Mo reduces the surface of titania and the dispersion of Rh particles originally sitting on titania is preserved on this reduced surface. The decrease of O-signal up to $\sim 600 \mathrm{~K}$ can be mainly attributed to desorption of CO (adsorbed during Rh-deposition) from the metal particles.

It is worthwhile to compare the behaviour of Rh-free, Mo-covered surface (Fig. 1B) with that of bimetallic layers. It can be seen that the Mo-signal remains constant up to $\sim 600 \mathrm{~K}$ in the presence of Rh (Fig. 3A), in contrast to the small decrease observed for the Rh-free surface. The Rh overlayer seems to hinder the surface diffusion of oxygen atoms, resulting in a somewhat suppressed surface oxidation of molybdenum. Elevating the temperature above $600 \mathrm{~K}$, a new phenomenon is reflected by the AES signals (Fig. 3A). Surprisingly, the decrease of Rh-signal is accompanied by an increase of Mo peak, what can be rationalized through a process in which Mo atoms get closer to while Rh atoms get farther from the surface. Comparing this observation with that presented in Fig. 2B, we can establish for the Mo-Rh bimetallic system formed on titania that above $700 \mathrm{~K}$ the AES signal of postdeposited metal decreases, while that of predeposited one increases irrespec- 



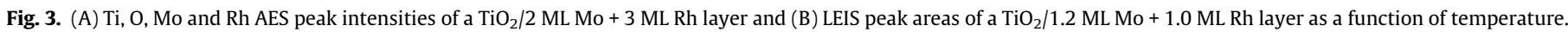

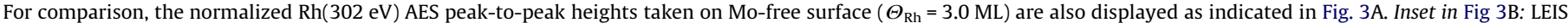
spectra obtained after (i) the deposition of $1.2 \mathrm{ML}$ of Mo followed by the deposition of $1 \mathrm{ML}$ of Rh, both at $330 \mathrm{~K}$ and annealing at (ii) $540 \mathrm{~K}$ and (iii) $900 \mathrm{~K}$.

tive of deposition sequences. Note that this phenomenon was also seen for lower Rh-coverages as well, on annealing the $\mathrm{TiO}_{2} / 2 \mathrm{ML}$ $\mathrm{Mo}+0.5 \mathrm{ML} \mathrm{Rh}$ and $\mathrm{TiO}_{2} / 0.5 \mathrm{ML} \mathrm{Rh}+2 \mathrm{ML}$ Mo layers (not shown). This can be explained by invoking the well-documented alloying between the two metals [12-14]. This alloying represents a driving force to the formation of sintered, mixed bimetallic particles, what seems to be in harmony with the increase of Ti and O AES signals above $\sim 800 \mathrm{~K}$.

In Fig. 3B LEIS peak areas are plotted as a function of temperature for the bimetallic layer produced by postdeposition of $\mathrm{Rh}$ (1 ML) onto a Mo-covered (1.2 ML) titania surface. From the nearly complete diminution of Rh LEIS peak areas (full squares) at $\sim 700 \mathrm{~K}$ we can conclude that the encapsulation of $\mathrm{Rh}$ is practically completed by this temperature. It is remarkable that the encapsulation is also finished at around $700 \mathrm{~K}$ both for the Mo-free (Fig. 2C, open triangles) and Mo-postdeposited (Fig. 2C, full triangles) surfaces, indicating that the presence of Mo could not hinder the migration of $\mathrm{TiO}_{x}$ onto the surface of rhodium particles, irrespective the deposition sequence. The annealing between 330 and $700 \mathrm{~K}$ (Fig. 3B) is accompanied by the decrease in the O/Ti LEIS ratio from 1.3 to 0.97 , according to the encapsulation of $\mathrm{Rh}$ by a reduced $\mathrm{TiO}_{x}(x<2)$ layer. The concomitant slight increase in the Mo LEIS peak area up to $550 \mathrm{~K}$ can be attributed to the desorption of gases $\left(\mathrm{CO}, \mathrm{H}_{2} \mathrm{O}\right)$ exposed to Mo during the deposition of Rh. Above $700 \mathrm{~K}$, where the encapsulation process is finished, the increase in the $\mathrm{O}$ and decrease in Ti LEIS signals indicate that the surface is reoxidized. The decrease in Mo-signal reflects the sintering of Mo-containing particles. Note that after annealing the bimetallic layer to $900 \mathrm{~K}$, the $\mathrm{O} / \mathrm{Ti}$ LEIS ratio amounts to 0.95 . This value is higher than the one characteristic of the stoichiometric titania surface $(\sim 0.75)$ for our samples. This is in accordance with the presence of $\mathrm{Rh}$ particles encapsulated by titania (documented in the literature with $\mathrm{TiO}_{x}, x<2$ composition) in the company of oxidized Mo particles. The uncovered titania surface tend to become stoichiometric due to oxidation above $850 \mathrm{~K}$ through ion-exchange with the bulk, as it is indicated on metal-free $\mathrm{TiO}_{2}$ surface by AES (Fig. 2B inset). As mentioned above based on AES measurements, alloying of Rh and Mo is significant at $900 \mathrm{~K}$. The complete lack of the Rh LEIS signal at this temperature indicates that $\mathrm{Rh}$ atoms located on the surface of alloy clusters are also encapsulated by titania.

\section{Conclusions}

(1) XPS data reveal that 3 ML of predeposited rhodium hinders the redox process between $\mathrm{TiO}_{2}$ and molybdenum at $330 \mathrm{~K}$. However, a moderate thermal activation (annealing to $600 \mathrm{~K}$ ) nearly diminishes the protecting effect of $\mathrm{Rh}$ against the reaction of Mo with $\mathrm{TiO}_{2}$ as shown by the similar extent of reduction in titania than for the Mo-free sample. This indicates a high enough mobility of O-atoms at $600 \mathrm{~K}$ for the redox process and is also connected to the fact that Rh does not form a continuous layer on $\mathrm{TiO}_{2}\left(\begin{array}{lll}1 & 1 & 0\end{array}\right)$ surface.

(2) Although thermodynamic data suggest that Rh-atoms prefer to locate on the surface of Mo-Rh alloy, there is no sign for site-exchange during deposition of Mo onto Rh particles at $330 \mathrm{~K}$ that is the kinetic hindrance is too large for this process at $330 \mathrm{~K}$.

(3) The presence of 1.2 ML Mo only slightly affects the encapsulation of Rh by titania; at around $\sim 700 \mathrm{~K}$ this process is nearly completed irrespective of the presence of Mo and the deposition sequence between Rh and Mo.

(4) Above $700 \mathrm{~K}$ there is indication for alloying between $\mathrm{Rh}$ and Mo particles. Although bulk phase materials mix at higher temperatures, the huge excess surface energy of nanoparticles and differences in the electronic structures compared to bulk materials may facilitate the alloy-formation.

\section{Acknowledgement}

Support by Hungarian National Foundation, OTKA NI69327, K69200 is gratefully acknowledged.

\section{References}

[1] Jingguang G. Chen, Carl A. Menning, Michael B. Zellner, Surface Science Reports 63 (2008) 201

[2] O. Ozturk, J.B. Park, S. Ma, J. Ratliff, J. Zhou, D.R. Mullins, D.A. Chen, Surf. Sci. 601 (2007) 3099.

[3] A.F. Carlsson, M. Naschitzki, M. Ba1umer, H.-J. Freund, J. Phys. Chem. B 107 (2003) 778 .

[4] E. Napetschnig, M. Schmid, P. Varga, Surf. Sci. 601 (2007) 3233.

[5] L. Bugyi, A. Berkó, L. Óvári, A.M. Kiss, J. Kiss, Surf. Sci. 602 (2008) (1650).

[6] L. Óvári, L. Bugyi, Z. Majzik, A. Berkó, J. Kiss, J. Phys. Chem. C 112 (2008) 18011.

[7] N.B. Shali, S. Sugunan, Mater. Res. Bull. 42 (2007) 1777.

[8] M.D. Wardinsky, W.C. Hecker, J. Phys. Chem. 92 (1988) 2602. 
[9] Eric E. Lowenthal, Larry F. Allard, Mure Te, Henry C. Foley, J. Mol. Catal. A 100 (1995) 129.

[10] K. Tomishige, I. Furakido, T. Yamagashi, S. Ito, K. Kunimori, Catal. Lett. 103 (2005) 15.

[11] Y. Izumi, K. Konishi, M. Tsukahara, D.M. Obaid, K. Aika, J. Phys. Chem. C 111 (2007) 10073.

[12] R. Lamber, N.I. Jaeger, A. Trunschke, H. Miessner, Catal. Lett. 11 (1991) 1

[13] R. Gürler, J. Mater. Sci. Lett. 18 (1999) 445.

[14] Stefano Curtaroloa, Dane Morgan, Gerbrand Ceder, Comput. Coupling Phase Diagrams Thermochem. 29 (2005) 163.

[15] A. Christensen, A.V. Ruban, P. Stoltze, K.W. Jacobsen, H.L. Skriver, J.K. Norskov, F. Besenbacher, Phys. Rev. B 56 (1997) 5822

[16] D.A. Storm, F.P. Mertens, M.C. Cataldo, E. Deciano, J. Catal. 141 (1993) 478

[17] C.-C. Yeh, Y.-H. Lai, W.-Y. Chu, C.-T. Yeh, W.-H. Hung, Surf. Sci. 565 (2004) 81

[18] N.M. Markovic, P.N. Ross Jr., Surf. Sci. Rep. 45 (2002) 117.

[19] R. Németh, J. Kiss, F. Solymosi, J. Phys. Chem. C 111 (2007) 1424

[20] L. Kövér, D. Varga, I. Cserny, J. Tóth, K. Tökési, Surf. Interf. Anal. 19 (1992) 9.

[21] A. Berkó, A. Magony, J. Szökö, Langmuir 21 (2005) 4562.
[22] L. Óvári, J. Kiss, Appl. Surf. Sci. 252 (2006) 8624.

[23] U. Diebold, Surf. Sci. Rep. 48 (2003) 53.

[24] G.E. Poirier, B.K. Hance, J.M. White, J. Phys. Chem. 97 (1993) 5965

[25] A. Berkó, G. Ménesi, F. Solymosi, Surf. Sci. 372 (1997) 202.

[26] B. Domenichini, V. Blondeau-Patissiera, M.J. Casanove, G.D. Lianc, S. Bourgeois, J. Cryst. Growth 263 (2004) 256. and references therein.

[27] J. Prunier, B. Domenichini, Z. Li, P.J. Moller, S. Bourgeois, Surf. Sci. 601 (2007) 1144.

[28] V. Blondeau-Patissier, B. Domenichini, A. Steinbrunn, S. Bourgeois, Appl. Surf. Sci. 175-176 (2001) 674.

[29] B. Domenichini, G.A. Rizzi, P. Krüger, M.D. Negra, Z. Li, M. Petukhov, G. Granozzi, PJ. Moller, S. Bourgeois, Phys. Rev. B 73 (2006) 245433.

[30] J.R. Kitchin, M.A. Barteau, J.G. Chen, Surf. Sci. 526 (2003) 323.

[31] A.M. Asaduzzaman, P. Kruger, Phys. Rev. B 76 (2007) 115412.

[32] M.A. Henderson, Surf. Sci. 419 (1999) 174.

[33] Q. Fua, T. Wagner, Surf. Sci. Rep. 62 (2007) 431

[34] G.A. Rizzi, A. Gian, A.E. Reeder, E. Askia, S. Agnoli, G. Granozzi, Surf. Sci. 600 (2006) 3345 . 